\title{
The BMP1 Gene Is Essential for Pathogenicity in the Gray Mold Fungus Botrytis cinerea
}

\author{
Li Zheng, Mathew Campbell, Jennifer Murphy, Stephen Lam, and Jin-Rong Xu \\ Novartis Agribusiness Biotechnology Research Inc., 3054 Cornwallis Road, Research Triangle Park, \\ NC 27709, U.S.A. \\ Accepted 14 March 2000.
}

In Magnaporthe grisea, a well-conserved mitogen-activated protein (MAP) kinase gene, PMK1, is essential for fungal pathogenesis. In this study, we tested whether the same MAP kinase is essential for plant infection in the gray mold fungus Botrytis cinerea, a necrotrophic pathogen that employs infection mechanisms different from those of $M$. grisea. We used a polymerase chain reaction-based approach to isolate MAP kinase homologues from $B$. cinerea. The Botrytis MAP kinase required for pathogenesis (BMP) MAP kinase gene is highly homologous to the $M$. grisea $P M K 1$. BMP1 is a single-copy gene. bmp1 gene replacement mutants produced normal conidia and mycelia but were reduced in growth rate on nutrient-rich medium. bmp1 mutants were nonpathogenic on carnation flowers and tomato leaves. Re-introduction of the wild-type BMP1 allele into the bmp1 mutant restored both normal growth rate and pathogenicity. Further studies indicated that conidia from bmp1 mutants germinated on plant surfaces but failed to penetrate and macerate plant tissues. bmp1 mutants also appeared to be defective in infecting through wounds. These results indicated that $B M P 1$ is essential for plant infection in $B$. cinerea, and this MAP kinase pathway may be widely conserved in pathogenic fungi for regulating infection processes.

Additional keywords: Botryotinia fuckeliana, MAPK.

Botrytis cinerea Pers.:Fr. (teleomorph: Botryotinia fuckeliana (de Bary) Whetzel) is a broad-host-range, necrotrophic pathogen that attacks well over 200 plant species (Jarvis 1977). It is the causal agent of gray mold diseases on many economically important fruits, vegetables, and flowers. B. cinerea can directly penetrate healthy plant tissues or infect through wounds. As a necrotrophic pathogen, B. cinerea depends on its ability to kill plant cells to establish plant infection and start a parasitic life cycle. Despite considerable research efforts in the past, the mechanisms by which $B$. cinerea penetrates into plant tissues and induces host cell death have not been well defined. Recently, an endopolygalacturonase

Corresponding author: Jin-Rong Xu; Current address: Department of Botany and Plant Pathology, Purdue University, West Lafayette, IN 47907, U.S.A.; Telephone: 1-765-496-6918; Fax: 1-765-496-6918; E-mail: xu@btny.purdue.edu

Nucleotide and/or amino acid sequence data can be found at the GenBank data base as accession number AF205375. gene, Bcpg1, was reported to be required for full virulence in B. cinerea (ten Have et al. 1998). However, while lesion sizes were reduced, Bcpgl gene replacement mutants were still pathogenic and displayed normal primary infection frequency. Cell wall-degrading enzymes may be involved in disease development, but other pathogenicity factors must exist for $B$. cinerea to penetrate and kill plant cells (for reviews, see Staples and Mayer 1995; Elad 1997). Limited studies have suggested that reactive oxygen species (ROS) and phytotoxic fungal metabolites might be involved in $B$. cinerea infection processes (Lurie et al. 1997; Rebordinos et al. 1996; Tiedemann 1997).

Fungal pathogens, like all other living organisms, respond to environmental cues and adjust their intracellular activities in order to grow or survive in different environmental conditions. In eukaryotic cells, the mitogen-activated protein (MAP) kinase pathways are involved in transducing a variety of extracellular signals (Pelech 1996; Robinson and Cobb 1997). The budding yeast Saccharomyces cerevisiae has five well-characterized MAP kinase cascades regulating fungal growth and differentiation processes such as pheromone response, pseudohyphal growth, osmoregulation, cell wall integrity, and ascospore formation (for review, see Gustin et al. 1998; Herskowitz 1995). Recently, MAP kinase signal transduction pathways were shown to be important for pathogenesis in several fungi (Lev et al. 1999; Mayorga and Gold 1999; Muller et al. 1999; Takano et al. 1999; Xu and Hamer 1996; $\mathrm{Xu}$ et al. 1998). In the rice blast fungus, Magnaporthe grisea, $P M K 1$, a MAP kinase gene functionally related to yeast $F U S 3 / K S S 1$, is essential for appressorium formation and invasive growth (Xu and Hamer 1996). In Colletotrichum lagenarium, gene replacement mutants of $C M K 1$ had no defect in vegetative growth, but were reduced in conidiation on rich media and conidia germination in water. $\mathrm{cmkl}$ mutants were nonpathogenic and failed to form appressoria (Takano et al. 1999). In C. heterostrophus, a PMK1 homologue, $C H K 1$, is also essential for appressorium formation on artificial or leaf surfaces (Lev et al. 1999). chkl gene replacement mutants had poorly developed aerial hyphae and failed to produce conidia. The chkl mutants were significantly reduced in virulence, often causing almost no signs of disease or only slight discoloration of the leaf. In Ustilago maydis, a MAP kinase gene, $u b c 3$ (= kpp2), homologous to $P M K 1$ has been characterized (Mayorga and Gold 1999; Muller et al. 1999). Mutants with this MAP kinase deleted had no growth or morphological defects but were dramatically reduced in mating, formation of 
filamentous dikaryons, and virulence (Mayorga and Gold 1999; Muller et al. 1999). In plants inoculated with $\Delta k p p 2$ mutants of solo pathogenic haploid strains, tumor formation was observed only on leaves and tumor diameter did not exceed $1 \mathrm{~mm}$. It has been suggested that multiple MAPKs may exist in $U$. maydis to regulate mating and pathogenic development (Muller et al. 1999; Kahmann et al. 1999). Interestingly, $C E K 1$, a Candida albicans MAP kinase gene homologous to $P M K 1$, is also involved in localized and systemic candidiasis (Csank et al. 1998; Guhad et al. 1998). It appears that the same MAP kinase pathway plays significant roles in pathogenesis in these fungi.

To test whether the $P M K 1$ pathway is also essential for fungal infection in necrotrophic pathogens, we have isolated and characterized the PMKl homologous gene BMPl (Botrytis MAP kinase required for pathogenesis) in $B$. cinerea. $B M P l$ is a single-copy gene with $94 \%$ identity to $P M K 1$. bmpl deletion mutants are defective in penetrating and killing plant cells, indicating that $B M P 1$ is also essential for pathogenesis in $B$. cinerea, which employs infection mechanisms different from those of $M$. grisea. The PMK1/BMP1 MAP kinase pathway may be widely conserved in fungal pathogens for regulating plant infection processes.

\section{RESULTS}

\section{BMP1 encodes a MAP kinase homologous to $M$. grisea PMK1.}

A polymerase chain reaction (PCR)-based screen was used to isolate MAP kinase homologues from $B$. cinerea with degenerate primers JM2 and JM5 (see Materials and Methods). A major band of $0.7 \mathrm{~kb}$ amplified with primer JM2 and JM5 was cloned in pBluescript SK. One PCR clone homologous to $M$. grisea PMK1 was identified and used as the probe to screen $B$. cinerea genomic and cDNA libraries. Sequence analysis of the resulting genomic and two cDNA clones revealed an open reading frame encoding a 356 amino acid protein that is $94 \%$ identical and $95 \%$ similar to $M$. grisea Pmk1 (Fig. 1A). We designated this gene as BMP1. BMPl is also highly homologous to Nectria haematococca FsMAPK (Li et al. 1997), Colletotrichum lagenarium CMK1 (Takano et al. 1999), C. heterostrophus CHK1 (Lev et al. 1999), and $U$. maydis ubc3 (Mayorga and Gold 1999), five fungal MAP kinase genes closely related to PMK1 (Fig. 1A). BMP1 is a single-copy gene in $B$. cinerea wild-type strains according to Southern blot analysis with genomic DNAs digested with EcoRI, BamHI, and HindIII (data not shown). The BMPI genomic clone contains four introns (one in the $5^{\prime}$ untranslated region) and has typical features of MAP kinases, including 11 protein kinase domains and double phosphorylation sites TEY (Fig. 1A). Phylogenetic analysis of amino acid sequences indicate that Bmp1 is more closely related to $M$. grisea Pmk1 and yeast Kss1/Fus3 and less related to other MAP kinases identified in $M$. grisea or yeast (Fig. 1B). These data strongly suggest that $B M P 1$ is the $P M K 1$ homologue in $B$. cinerea.

\section{$B M P 1$ is not essential for fungal growth.}

To examine the function of BMPl in $B$. cinerea, we isolated bmpl gene replacement mutants. The $B M P 1$ gene replacement vector pMac20 was constructed by replacing the $B M P 1$ coding region with the bacterial hygromycin phosphotransferase gene $h p h$ (Fig. 2A). Undigested pMac20 DNA was used to transform the wild-type isolate A-1-3. All hygromycinresistant transformants were screened by PCR with primers BK2F and H855R (data not shown). Putative bmpl gene replacement transformants with the 1.2-kb, PCR-amplified product were further verified by PCR with $B M P 1$ primers Mac74 and Mac295. Homokaryotic bmpl mutants will lack the $0.7-\mathrm{kb}$ PCR product. Transformant KA11 was one of these putative bmpl mutants isolated in this PCR screening. The BMP1 gene replacement event in KA11 was confirmed by Southern blot analysis (Fig. 2B). When probed with the $2.0-\mathrm{kb}$ EcoRI fragment from pMac11 (Fig. 2A), KA11 lacked the wild-type, 2.0-kb EcoRI band but had the 1.0-kb EcoRI band derived from the gene replacement vector (Fig. 2B).

The mutant KA11 formed typical grayish colonies on $2 \times \mathrm{V} 8$ medium and produced abundant quantities of normal macroconidia and microconidia. No obvious reduction or delay in conidia germination was observed with macroconidia collected from bmpl mutants resuspended in $0.5 \%$ glucose. However, in comparison with wild-type strain A-1-3, KA11 was reduced in vegetative growth rate on $2 \times \mathrm{V} 8$ agar (Table 1). Further tests with PDA and $5 \times$ YEG $(0.5 \%$ yeast exract and $1 \%$ glucose) indicated that this reduction in fungal growth is not medium dependent (data not shown).

To determine whether this reduction in growth rate is directly related to the $b m p l$ deletion, we cloned the $2.8-\mathrm{kb} X b a \mathrm{I}$ fragment containing the wild-type $B M P 1$ gene (Fig. 2A) into pAC905. Undigested DNA of the resulting plasmid pLZ11 was used to transform bmpl mutant KA11. Bleomycinresistant transformants grown on medium containing $50 \mu \mathrm{g}$ of bleomycin per $\mathrm{ml}$ were screened by PCR with $B M P 1$ primers Mac74 and Mac295 and confirmed by Southern blot analysis for the presence of the wild-type BMP1 allele (data not shown). Complemented $B M P 1$ transformants grew at rates comparable to the wild-type strain A-1-3 (Table 1). Thus, reintroduction of the wild-type $B M P 1$ allele restored the growth defect in bmpl mutants.

To prove that this growth defect is not strain dependent, we generated two additional bmpl gene replacement mutants, $\mathrm{KB} 2$ and KB4, in the B. cinerea strain B05-10 (Fig. 2C). Both KB2 and KB4 grew slower than B05-10 on $2 \times$ V8 agar (Table $1)$. These data suggest that, while $B M P 1$ is not essential for fungal growth or conidiation, it may be involved in maintaining optimal mycelial growth rates in $B$. cinerea.

\section{$B M P 1$ is essential for plant infection.}

In $M$. grisea, pmkl mutants are defective in appressorium formation and plant infection (Xu and Hamer 1996). Interestingly, we found that bmpl mutants in B. cinerea were also nonpathogenic. Necrotic lesions were visible $36 \mathrm{~h}$ post inoculation (hpi) on carnation flowers sprayed with wild-type strain A-1-3 conidia. At $72 \mathrm{hpi}$, these lesions had enlarged and most of the flowers were rotted (Fig. 3A). In contrast, no necrotic lesions were observed in flowers sprayed with conidia from the bmpl deletion mutant KA11 (Fig. 3A). We repeated this infection assay with detached carnation petals (data not shown). Carnation flower petals inoculated with wild-type strains A-1-3 and B05-10 developed lesions at the inoculation sites by 72 hpi. No lesions were observed on the petals inoculated with bmp1 mutants KA11, KB2, and KB4, even after prolonged incubation time of 7 days (data not shown). 
In addition to carnation flower infection, we also assayed bmpl mutants on tomato leaves and confirmed that bmpl mutants were nonpathogenic. When tomato leaves were inoculated with drops of $B$. cinerea conidial suspensions, over $90 \%$ of the sites inoculated with wild-type conidia developed lesions (Fig. 3B). On the same leaves, the sites inoculated with conidia from $\mathrm{bmpl}$ mutants failed to develop any lesions. We repeated this infection assay at both $4^{\circ} \mathrm{C}$ (Fig. $3 \mathrm{~B}$ ) and $20^{\circ} \mathrm{C}$ (data not shown) and obtained the same results. Wild-type strains caused necrotic lesions visible at 96 hpi, whereas bmpl mutants did not cause any lesions (Fig.
3B). We also assayed B. cinerea infection on rose flowers and found that bmpl mutants could not infect rose flower petals. Furthermore, complemented BMP1 transformants generated by re-introducing the wild-type $B M P 1$ allele into KA11 were fully pathogenic on carnation and rose flowers and on tomato leaves (data not shown). All the infection assays described above were conducted at least four times with a minimum of 20 flower petals or tomato leaves, and we did not observe any lesions formed by bmpl mutants. Thus, we conclude that $B M P 1$ is essential for fungal pathogenesis in B. cinerea.

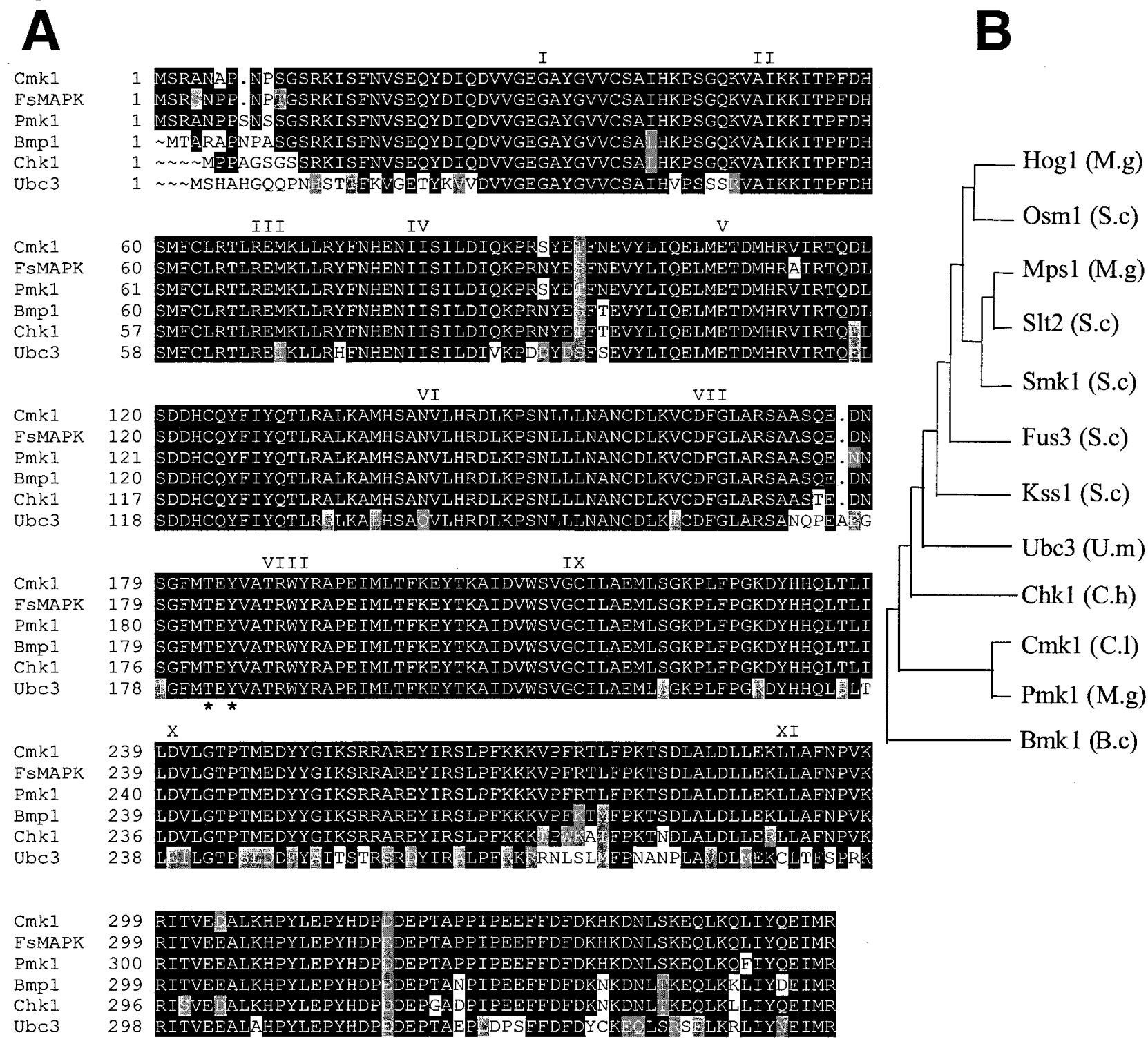

Fig. 1. Relatedness of the predicted amino acid sequence of $B M P 1$ to other fungal mitogen-activated protein (MAP) kinases. A, Sequence alignment of Bmp1 with Magnaporthe grisea Pmk1, Nectria haematococca FsMAPK, Colletotrichum heterostrophus Chk1, C. lagenarium Cmk1, and Ustilago maydis Ubc3 MAP kinases. Black boxes, identical residues; similar residues are shaded. The 11 protein kinase domains are labeled on top in Roman numerals. The tyrosine $(\mathrm{T})$ and threonine $(\mathrm{Y})$ residues, two putative phosphorylation sites for MAP kinase kinase, are identified by asterisks. GenBank accession numbers: AF205375 for BMP1, U70134 for PMK1, U52963 for FsMAPK, AF178977 for CHK1, AF174649 for CMK1, and AF170532 for ubc3. B, Relatedness of Bmp1 to MAP kinases Fus3, Kss1, Hog1, Slt2, and Smk1 from S. cerevisiae, Pmk1, Osm1, and Mps1 from M. grisea, and Chk1, Cmk1, and Ubc3 from other phytopathogenic fungi. Phylogram was prepared with the GROWTREE program (Genetic Computer Group, Madison, WI). GenBank accession numbers: M31132 for FUS3, M26398 for KSS1, L06279 for HOG1, X59262 for SLT2, L35047 for SMK1, AF184980 for OSM1, and AF020316 for MPS1. 
In $M$. grisea, $P M K 1$ is essential for both appressorium formation and invasive growth. pmkl gene replacement strains could not infect rice leaves through wounds (Xu and Hamer 1996). To determine whether bmpl mutants have a similar defect, carnation flower petals were wounded with a needle and inoculated with droplets of conidial suspensions. While wildtype strains formed spreading lesions over the inoculation sites, bmpl mutant KA11 caused only very localized necrosis at the wounding sites (data not shown). These observations suggest that $B M P 1$ is also important for fungal growth after penetration in B. cinerea.

\section{bmp1 mutants do not elicit plant defense responses.}

To define the pathogenicity defects in bmpl mutants, we examined carnation flower petals inoculated with conidia from wild-type A-1-3 and bmpl mutant KA11 with light and epifluorescence microscopy. Wild-type conidia caused microscopic lesions and elicited plant cell autofluorescence as early

A

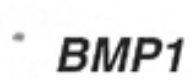

$1 \mathrm{~kb}$
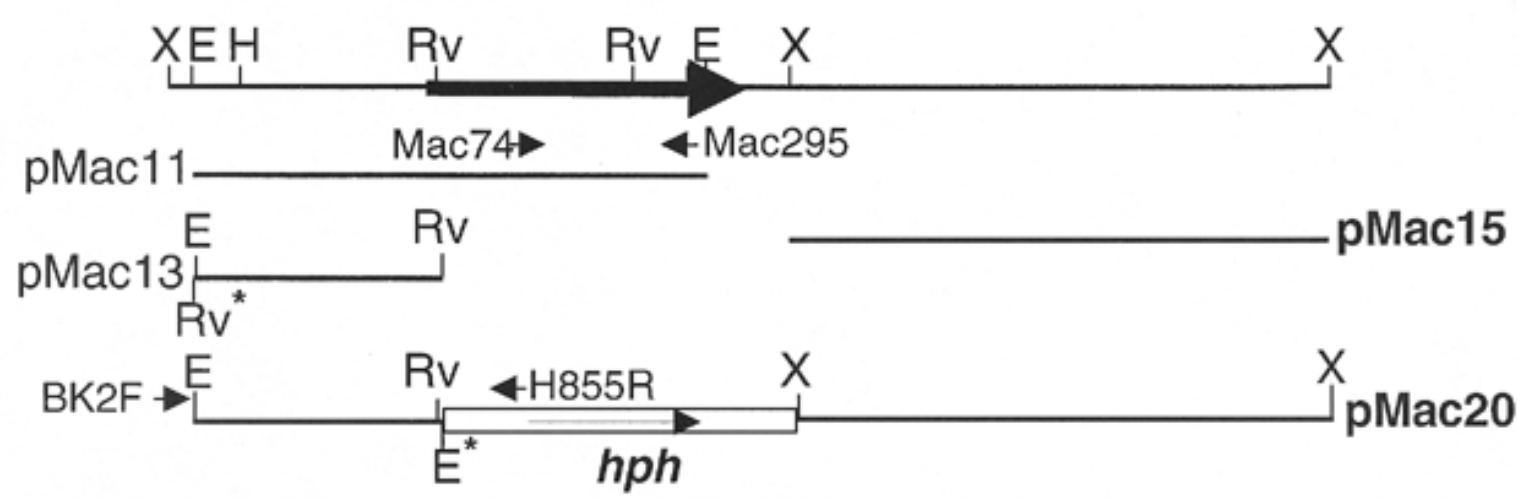

B

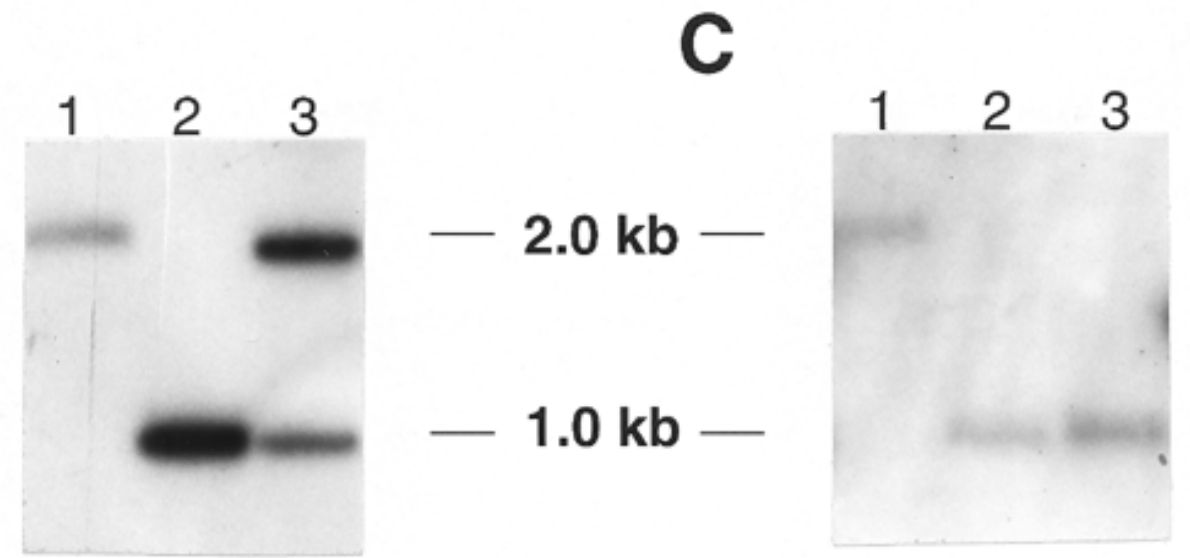

Fig. 2. $B M P 1$ gene replacement. A, Physical map of $B M P 1$ genomic region and gene replacement vector pMac20. Restriction enzymes: (E) EcoRI; (H) HindIII; (Rv) EcoRV; (X) XbaI. EcoRV and EcoRI sites derived from cloning vector pBluescript SK are marked by '*'. Arrows indicate orientations of the BMPl and $h p h$ genes. Mac74, Mac 295, BK2F, and H855R are four primers used for screening gene replacement mutants. B, Southern blot analysis of genomic DNAs of the wild-type strain A-1-3 (lane 1), BMP1 gene replacement transformant KA11 (lane 2), and KA11 transformed with pLZ11, which contains the entire BMP1 gene (lane 3). C, Southern blot analysis of wild-type strain B05-10 (lane 1), BMP1 gene replacement transformants KB2 (lane 2) and KB4 (lane 3). All DNA samples were digested with EcoRI. Blots were probed with the 1.0-kb EcoRI fragment from pMac20. While both A1-3 and B05-10 have the wild-type 2.0-kb band, all transformants that have undergone replacement of the BMP1 gene with the $h p h$ gene have only the $1.0-\mathrm{kb}$ fragment. The complemented bmpl transformant (B, lane 3$)$ has both the 1.0- and 2.0-kb EcoRI bands.

Table 1. Growth of the wild-type strains and bmp1 mutants ${ }^{\mathrm{a}}$

\begin{tabular}{|c|c|c|c|c|c|c|}
\hline Incubation time & A-1-3 (wild type) & KA11 (bmp1) & CA11 $(B M P 1)^{b}$ & B05-10 (wild type) & KB2 (bmp1) & KB4 (bmp1) \\
\hline $36 \mathrm{~h}$ & $25.2 \pm 3.3$ & $4.4 \pm 1.7$ & $27.2 \pm 4.6$ & $30.0 \pm 1.4$ & $3.2 \pm 1.1$ & $4.0 \pm 0.0$ \\
\hline $60 \mathrm{~h}$ & $60.4 \pm 3.8$ & $19.2 \pm 1.1$ & $59.2 \pm 4.1$ & $64.0 \pm 0.0$ & $16.8 \pm 3.3$ & $16.7 \pm 1.2$ \\
\hline $84 \mathrm{~h}$ & $97.2 \pm 8.6$ & $38.3 \pm 3.6$ & $98.4 \pm 5.5$ & $98.0 \pm 7.4$ & $30.0 \pm 3.7$ & $22.7 \pm 3.0$ \\
\hline
\end{tabular}

${ }^{a}$ Fungal growth was measured by the diameter of colonies (in millimeters) as 36, 60, and 84 h after inoculation. Standard deviations were calculated based on five replicates.

${ }^{\text {b }}$ CA11 was one of the complemented BMP1 transformants of KA11 (transformed with pLZ11). 
as 16 hpi (data not shown). In contrast, the bmpl mutant did not cause either microscopic lesions or autofluorescence even after prolonged incubation.

To further examine the behavior of bmpl conidia on the plant surface, carnation petals inoculated with $B$. cinerea were stained with trypan blue and examined microscopically. Trypan blue stains fungal hyphae but not healthy plant cells. After germination, wild-type A-1-3 germ tubes could penetrate into the host epidermal cells, and only short germ tubes were observed on plant surfaces at 16 hpi (Fig. 4A). Plant cell autofluorescence was detected only at the penetration sites of wild-type conidia (Fig. 4B). On carnation flowers inoculated with bmpl mutants, conidia germinated, but no penetration or plant cell autofluorescence were observed even at 72 hpi (Fig. 4C and D). Germ tubes from bmpl mutants formed long, thin hyphae on carnation flower surfaces (Fig. 4C). Because the deposition of autofluorescent compounds at penetration sites is part of the plant defense responses triggered by fungal penetration attempts, these results suggested that bmpl germ tubes formed on plant surfaces did not attempt to invade or penetrate, or failed to produce molecules triggering the plant defense responses.

\section{bmp1 mutants fail to penetrate plant cells.}

To further characterize the infection defect of bmpl mutants, carnation flower petals inoculated with $B$. cinerea conidia were examined by scanning electronic microscopy (SEM). Wild-type conidia germinated and penetrated plant cells without forming any well-defined infection structures (Fig. 5A and C). Plant cells beneath the penetrating germ tubes were collapsed (Fig. 5). This penetration process appeared to be a rapid process because only short germ tubes were observed, and plant cell death occurred as early as 16 hpi. Conidia from bmpl mutant KA11 germinated, but the germ tubes grew as thin mycelium on the plant surface without any penetration (Fig. 5C). The underlying plant cells were not collapsed or deformed (Fig. 5D). Similar results were obtained when infected tomato leaves were examined by SEM. We observed penetration and plant cell collapse only in tomato leaves infected with the wild-type but not with bmpl mutant conidia (data not shown). bmpl mutants seem to be defective in regulating the penetration process and triggering plant cell death.

\section{DISCUSSION}

B. cinerea infects a wide range of plants including almost all dicot species and many monocots (Elad 1997). Under favorable conditions, the gray mold fungus can cause severe damage on many crops pre-harvest or during storage. Being a successful pathogen on so many plant species, $B$. cinerea must employ several mechanisms of pathogenicity, such as enzymemediated penetration, toxin production, and detoxification, to overcome host defense systems and establish infection (Staples and Mayer 1995).

In this study, we isolated and characterized the BMPl MAP kinase gene from $B$. cinerea. $B M P 1$ is highly homologous to M. grisea PMK1 (Xu and Hamer 1996) and its homologues from other phytopathogenic fungi (Lev et al. 1999; Mayorga and Gold 1999; Muller et al. 1999; Takano et al. 1999). bmpl deletion mutants produced normal conidia and mycelia but were reduced in growth rate. Interestingly, $b m p l$ mutants were nonpathogenic on carnation flowers and tomato leaves. Further examination indicated that $b m p l$ conidia had no defect in conidia germination and could grow on plant surfaces. However, they were unable to penetrate and cause necrotic lesions.
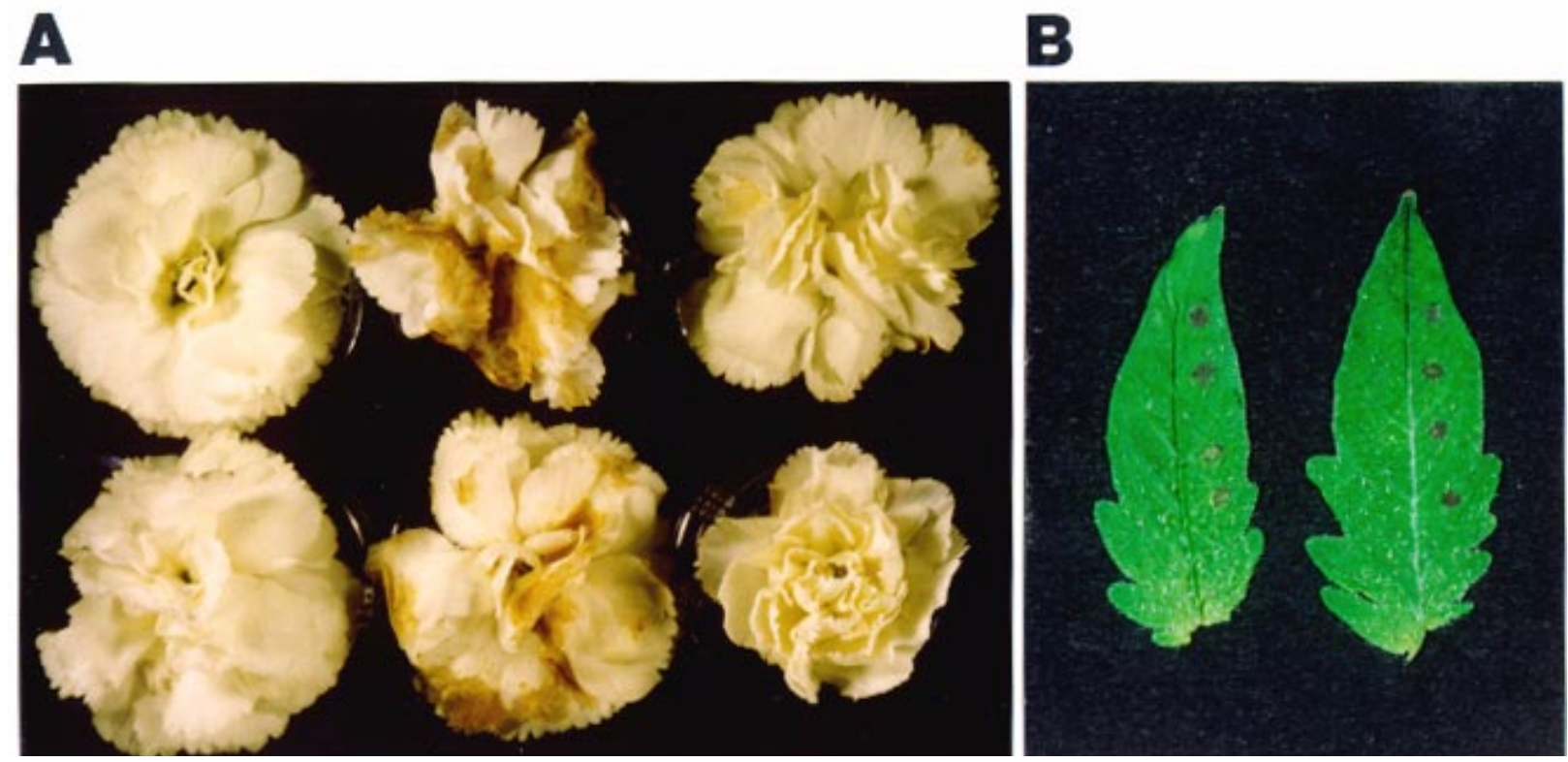

Fig. 3. Infection assays on carnation flowers and tomato leaves. A, Carnation flowers were sprayed with conidial suspensions and photographed at $72 \mathrm{~h}$ post inoculation (hpi). While typical gray mold disease symptoms were observed on flowers sprayed with wild-type strain A-1-3 (middle), no obvious disease symptoms occurred on flowers inoculated with bmpl mutant KA11 (right) or water controls (left). B, Tomato leaves inoculated with conidial suspensions prepared from bmpl mutants (left parts of leaves) and wild-type strains (right part of leaves). Leaf on the left was inoculated with KA11 and A-1-3 (four inoculation sites on both sides). Leaf on the right was inoculated with KB2 and B05-10. Both wild-type strains A-1-3 and B05-10 caused necrosis lesions, but no symptoms were observed at the inoculation sites of bmp1 mutants KA11 and KB2 at 96 hpi. 
Microscopic examination clearly indicated that bmpl mutants were defective in penetrating and killing plant cells. We did not observe any obvious attempts to penetrate by bmpl mutants and did not observe cell deformation in the underlying plant cells. Furthermore, bmpl mutants failed to elicit autofluorescence (an indication of plant defense responses) and failed to infect through wounds. Although $B$. cinerea is a necrotrophic pathogen that preferentially infects through wounds, we found that bmpl mutants were defective in infection through wounds on carnation flowers. It is evident that $B$. cinerea and $M$. grisea share related MAP kinase pathways for plant infection, even though they cause different diseases and have different infection mechanisms.

Recently, the $P M K 1$ homologue $(C M K 1)$ was also found to be essential for pathogenesis in C. lagenarium (Takano et al. 1999). In addition, MAP kinases homologous to $P M K 1$ were reported to be important for fungal virulence in another ascomycete, C. heterostrophus, one basidiomycete, U. maydis, and the asexual human pathogen C. albicans (Csank et al. 1998; Guhad et al. 1998; Lev et al. 1999; Mayorga and Gold 1999; Muller et al. 1999). Interestingly, in all three appressoriumforming, phytopathogenic fungi studied (M. grisea, C. lagenarium, and $C$. heterostrophus), appressorium formation was abolished in mutants deleted of the PMK1 or its homologues (Lev et al. 1999; Takano et al. 1999; Xu and Hamer 1996). The evidence strongly supports the hypothesis that the $P M K 1$ MAP kinase pathway is widely conserved among many fungi and plays an important role in pathogenesis.

Besides being involved in plant infection, the PMK1 homologues from different fungi also play diverse roles in fungal growth and differentiation. While pmkl mutants had normal growth rate and had no defect in conidia germination in M. grisea (Xu and Hamer 1996), C. lagenarium cmk1 mutants were reduced in conidia germination on artificial or plant surfaces (Takano et al. 1999). B. cinerea bmpl mutants had no defect in conidia germination but were reduced in vegetative growth. In $C$. heterostrophus, chkl gene replacement mutants were defective in producing aerial hyphae, failed to produce any conidia, and were female sterile (Lev et al. 1999). In $U$. maydis, deletion of the $u b c 3$ gene had no effect on fungal growth and cell morphology, but reduced mating responses (Kahmann et al. 1999; Muller et al. 1999). Interestingly, disruption of the CEK1 gene also adversely affects the seruminduced, mycelial growth in C. albicans (Csank et al. 1998). Therefore, the PMK1 signal transduction pathway may respond to different signals and regulate different processes in
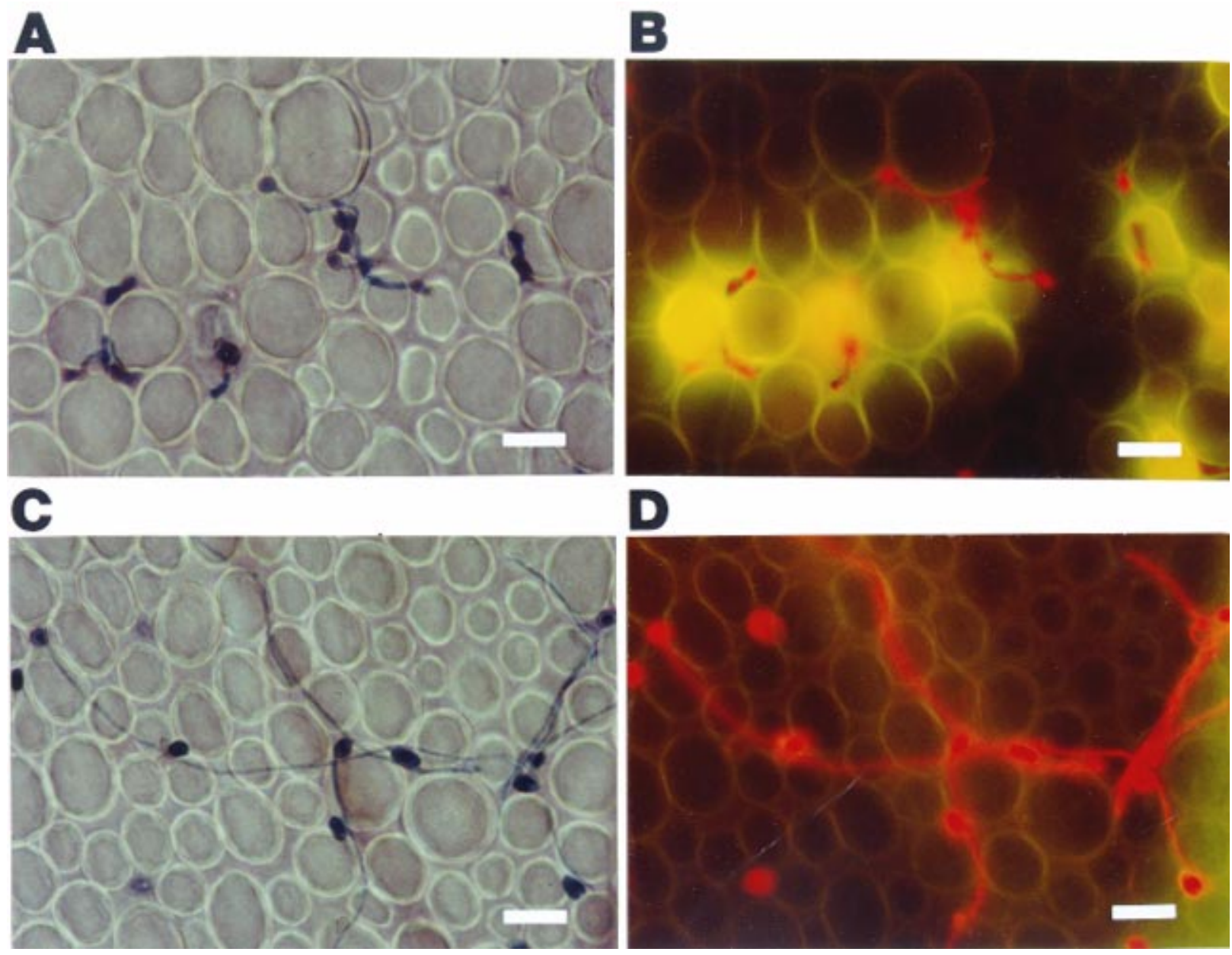

Fig. 4. Trypan blue staining of infected carnation petals. A, Wild-type A-1-3 conidia penetrated plant tissues shortly after germination and only short germ tubes were observed. B, Under epifluorescent microscopy, some of the plant cells accumulated autofluorescent materials in response to fungal infection. C and D, Conidia from bmpl mutant KA11 germinated and formed long germ tubes on the petal surface but failed to penetrate. Trypan bluestained conidia and germ tubes were blue under transmission light and red under UV-light. Bar $=30 \mu \mathrm{m}$. 
these diverse fungi. Most likely, $B M P 1$ is somehow involved in recognizing certain environmental factors and regulating fungal hyphal tip growth.

Although further experiments are needed to define the precise functions of the $B$. cinerea $B M P 1$ gene, there are several processes in which $B M P 1$ may be directly involved. Similar to $P M K 1, B M P 1$ may control the development or the process of the infection-related morphogenesis. While $B$. cinerea does not produce well-defined, melanized appressoria like $M$. grisea, the germ tubes have to arrest tip growth and change the direction of growth to penetrate plant cells. In fact, the germ tube tips usually swell slightly and can form appressorium-like infection structures in $B$. cinerea (Backhouse and Willetts 1987; Hammer and Evenson 1994; Rijkenberg et al. 1980; Verhoeff 1980). BMP1 may also control the expression and secretion of cell wall-degrading enzymes that are involved in plant penetration. In $B$. cinerea, an endopolygalacturonase gene was reported to be involved in pathogenesis (ten Have et al. 1998). Interestingly, the Kss1 MAP kinase pathway also regulates the expression of an endopolygalacturonase gene, $P G U 1$, in yeast (Madhani et al. 1999). In addition, BMPI may regulate the production of elicitors or phytotoxins that are important for penetration and disease development. Like many necrotrophic pathogens, $B$. cinerea may also produce phytotoxic compounds to suppress plant defense responses or trigger plant cell death at infection sites (Cutler et al. 1996; Duran et al. 1999; Rebordinos et al. 1996).
Transforming DNA can efficiently integrate into the $B$. cinerea genome by homologous recombination. The highest reported homologous recombination frequency is $80 \%$ with a $7-$ $\mathrm{kb}$ fragment containing the nitrate reductase gene (Levis et al. 1997). In this study, we examined the frequency of the gene replacement event in the $B$. cinerea wild-type strain B05-10 at the $B M P 1$ locus. When flanking homologous sequences 500 and 100 bp long were tested, gene replacement events occurred in 16 out of 24 transformants. Even when flanking sequences were as short as $100 \mathrm{bp}$ on both sides, two out of 13 transformants examined were bmpl gene replacement mutants. Recently, we used the PCR-based approach (Baudin et al. 1993) with 80-bp flanking sequences to successfully generate gene replacement mutants for several $B$. cinerea genes, including a yeast SAR1 homologue encoding a GTP-binding protein (R. Lamm, J.-R. Xu, and S. Lam, unpublished data). These preliminary data indicated that gene replacement is very efficient and does not require long flanking sequences in $B$. cinerea. This feature makes $B$. cinerea a fungal pathogen system suitable for large-scale gene replacement analysis.

\section{MATERIALS AND METHODS}

\section{Strains and growth conditions.}

The wild-type $B$. cinerea strain A-1-3 was isolated from diseased rose flowers and provided by Philip Hammer (Novartis Agribusiness Biotechnology Research, Research
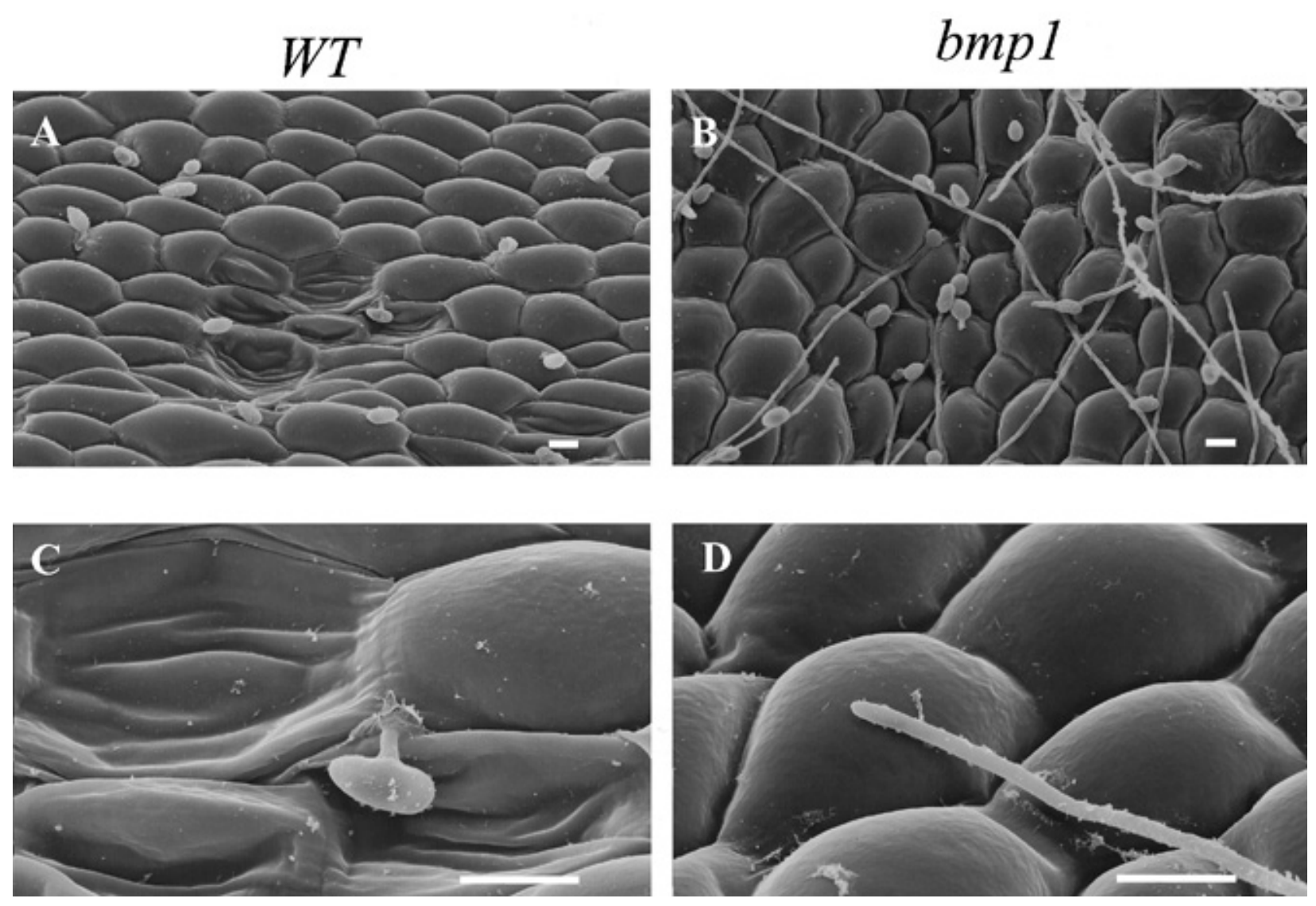

Fig. 5. Infected carnation petals examined by scanning electronic microscopy. A and $\mathbf{C}$, Carnation petals inoculated with wild-type A-1-3 conidia. Plant cells collapsed as a result of Botrytis cinerea infection. B and D, Conidia from bmp1 mutant KA11 germinated and grew on carnation flower surface, but penetration and plant cell collapse were not observed. Bar $=10 \mu \mathrm{m}$. 
Triangle Park, NC). Strain B05-10 was derived from SAS56 treated with benomyl (Buttner et al. 1994). Strain BC29 was isolated from diseased gerbera (Wubben et al. 1999). All B. cinerea strains were cultured on $2 \times \mathrm{V} 8$ agar $(36 \%$ V8 juice, $0.2 \% \mathrm{CaCO}_{3}, 2 \%$ Bacto-agar) at $20^{\circ} \mathrm{C}$ for conidiation with a 12-h photoperiod. Mycelia were collected from liquid cultures grown in $5 \times$ YEG $(0.5 \%$ yeast extract, $2 \%$ glucose $)$ with shaking at $150 \mathrm{rpm}$ (Lab-Line 3527 environmental shaker, Lab-Line Instruments, Melrose Park, IL) at $20^{\circ} \mathrm{C}$. Singlespore isolates were obtained with the Singer MSM micromanipulator (Singer Instruments, Somerset, UK). Conidia were germinated on $3 \%$ water agar overnight and then transferred individually to $2 \times \mathrm{V} 8$ agar containing $100 \mu \mathrm{g}$ of hygromycin B per $\mathrm{ml}$ (CalBiochem, La Jolla, CA) or $50 \mu \mathrm{g}$ of bleomycin or zeocin per ml (Sigma-Aldrich, St. Louis, MO). To measure fungal growth rate, mycelium plugs $(2 \times 2 \mathrm{~mm})$ from 1-weekold cultures were inoculated in the center of $2 \times \mathrm{V} 8$ agar plates. After incubation at $20^{\circ} \mathrm{C}$ for 36,60 , and $84 \mathrm{~h}$, fungal growth was recorded as the colony diameter.

\section{Cloning of the $B M P 1$ gene.}

Degenerate PCR primers JM2 (CARGARYTNATGGA RAC) and JM5 (TCRTTNGGRTCRTGRTA) were designed according to the conserved amino acid sequences QELMET and YHDPND of yeast MAP kinases FUS3, KSS1, and SPK1 (Krisak et al. 1994). Primers JM2 and JM5 were used to amplify MAP kinase homologues from $B$. cinerea by a PCR consisting of 30 cycles of $1 \mathrm{~min}$ at $94^{\circ} \mathrm{C}, 1 \mathrm{~min}$ at $48^{\circ} \mathrm{C}$, and 2 min at $72^{\circ} \mathrm{C}$, followed by $5 \mathrm{~min}$ at $72^{\circ} \mathrm{C}$. PCR products amplified from $\mathrm{BC} 29$ genomic DNA with these two primers with Vent DNA polymerase (New England Biolabs, Beverly, MA) were cloned in the SmaI site of pBluescript SK (Stratagene, La Jolla, CA) and sequenced. DNA sequences were analyzed with the DNASIS program (Hitachi Software, Santa Clara, CA). Homologue search of DNA/protein sequence data bases was performed with the BLAST programs (Altschul et al. 1997). One PCR clone, pJMM66, was found to be homologous to the $M$. grisea PMK1 gene. pJMM66 was then used to screen a BC29 Lambda DASH II (Stratagene) genomic library and a BC29 Lambda ZAP II (Stratagene) cDNA library that was constructed with RNAs isolated from mycelia grown in liquid 5× YEG.

\section{BMP1 gene replacement vector construction and $b m p 1$ mutant screen.}

To construct the $B M P 1$ gene replacement vector, the $2.0-\mathrm{kb}$ EcoRI fragment containing part of the $B M P 1$ gene and its upstream region was cloned in the EcoRI site of pBluescript SK (Stratagene) as pMac11 (Fig. 2A). A 1.0-kb EcoRV fragment from pMac11 (Fig. 2A; one of the EcoRV sites is from the multiple cloning site of pBluescript SK) was then subcloned into the EcoRV site of pBluescript SK as pMac13. The 1.4-kb HpaI fragment containing the hph gene from pCB1003 (Carroll et al. 1994) was then cloned into the SmaI site on pMac13. The resulting plasmid was digested with $X b a \mathrm{I}$ and ligated with the $X b a \mathrm{I} 2.6-\mathrm{kb}$ fragment containing the $B M P 1$ downstream sequence to create the $B M P l$ gene replacement vector pMac20 (Fig. 2). The orientations of subcloned fragments in pMac20 were confirmed by sequencing with primers H855R (Fig. 2A), T3, and T7 (the latter two primers flanking the multiple cloning sites of pBluescript SK).
Undigested pMac20 was used to transform wild-type $B$. cinerea strains as described (van Kan et al. 1997). Transformants resistant to $100 \mu \mathrm{g}$ of hygromycin B per ml were purified by single-spore isolation. Genomic DNAs were isolated from these transformants as described (Irelan et al. 1993) and used in PCRs with primers BK2F (CACACTTTACCAT CTGAAGT) and H855R (GCTGATCTGACCAGTTGC). The PCR conditions involved 30 cycles of $1 \mathrm{~min}$ at $94^{\circ} \mathrm{C}, 1 \mathrm{~min}$ at $52^{\circ} \mathrm{C}$, and $2 \mathrm{~min}$ at $72^{\circ} \mathrm{C}$, followed by $5 \mathrm{~min}$ at $72^{\circ} \mathrm{C}$. Because the $\mathrm{BK} 2 \mathrm{~F}$ primer sequence was not present on the gene replacement vector pMac20, only transformants that have undergone homologous recombination between pMac20 and the $B M P 1$ genomic sequence will have the $1.2-\mathrm{kb}$ PCR product. All putative $b m p 1$ gene replacement mutants were then further purified by single-spore isolation and screened by PCR with BMP1 primers Mac74 (TTATCTATCAAACCCTGCGAGCC) and Mac295 (GCTTCAGTGCTTCTTCGACAGTG). Putative bmpl gene replacement transformants were further confirmed by Southern blot analysis. The BMPl complementation vector pLZ11 was constructed by cloning the $2.8-\mathrm{kb} X b a$ I fragment containing the wild-type $B M P 1$ gene (Fig. 2) into the $X b a I$ site of pAC905. The plasmid pAC905 was provided by John Hamer at Purdue University (West Lafayette, IN). It contains the bleomycin resistance gene of Streptoalloteichus hindustanus (Mattern et al. 1988) under the control of the promoter from the M. grisea retroelement grasshopper (Dobinson et al. 1993).

\section{Infection assays on tomato leaves and carnation flowers.}

Conidia were collected from 2-week-old $B$. cinerea cultures and resuspended in water or $1 \%$ glucose to a final concentration of $2 \times 10^{5}$ conidia per ml. Carnation flowers were sprayed with conidial suspensions and incubated in a sealed glass beaker to obtain a high humidity. For infection assays with carnation flower petals, a droplet of $20 \mu \mathrm{l}$ of the conidial suspension was placed on each petal. Infected carnation petals were incubated on a Whatman filter paper soaked with sterile water containing $50 \mu \mathrm{g}$ of ampicillin per $\mathrm{ml}$ and sealed in a petri dish. For assaying infection through wounds, carnation petals were gently punched with a sterile needle before they were inoculated. All infection assays with carnation flowers were incubated at $20^{\circ} \mathrm{C}$ with a 12 -h photoperiod. Disease symptoms were expressed as necrotic lesions. Autofluorescence was examined with a Nikon Eclipse epifluorescence microscope. For pathogenicity tests on tomato leaves, four droplets of $1 \mu \mathrm{l}$ of $\mathrm{bmpl}$ or wild-type conidial suspensions (2 $\times 10^{5}$ conidia per $\mathrm{ml}$ in $0.01 \%$ Tween $20,0.06 \mathrm{M} \mathrm{KH}_{2} \mathrm{PO}_{4}$, $0.01 \mathrm{M}$ glycine, and $0.1 \mathrm{M}$ glucose) were inoculated on the left side or right side of each leaflet, respectively. Inoculated leaves were incubated at 4 or $20^{\circ} \mathrm{C}$ (ten Have et al. 1998) on a Whatman filter paper soaked with sterile water sealed in a petri dish. Symptoms were scored 4 days after inoculation.

\section{Trypan blue staining and SEM examination.}

Infected carnation flower petals were placed into wells of a 24-well plate and overlaid with lactophenol-trypan blue dye (a fresh mixture of $9.3 \mathrm{ml}$ of unsaturated phenol, $10 \mathrm{ml}$ of lactic acid, $10 \mathrm{ml}$ of $1 \mathrm{mg}$ trypan blue per $\mathrm{ml}$ ) pre-warmed to 50 to $65^{\circ} \mathrm{C}$. Air bubbles were removed by placing the samples in a vacuum desiccator for $5 \mathrm{~min}$. The samples were then heated in a microwave oven at 5- to 10-s intervals until the dye boiled. After staining overnight, the trypan blue dye was rinsed off. 
Infected carnation petals were cleared by incubating overnight in a $250 \%(\mathrm{wt} / \mathrm{vol})$ chloral hydrate solution and examined under transmission and epifluorescence microscopy. Sample preparation and SEM examination were performed as previously described (Hammer and Evenson 1994).

\section{ACKNOWLEDGMENTS}

We thank Karen Corfield and Randy Lamm for helping with the fungal transformation, Philip Hammer for providing wild-type Botrytis cinerea isolate A-1-3, Paul Tudzynski for the strain B05-10, and Jan van Kan for strain BC29 and insightful discussions. We also thank Larry Dunkle, Thomas Gaffney, and three anonymous reviewers for critical reading of the manuscript. We gratefully acknowledge the expert technical assistance of Philip Hammer in Botrytis cinerea infection assay and An Hu in DNA sequencing.

\section{LITERATURE CITED}

Altschul, S. F., Madden, T. L., Shaffer, A. A., Zhang, Z., Miller, W., and Lipman, D. J. 1997. Gapped BLAST and PSI-BLAST: A new generation of protein database search programs. Nucleic Acids Res. 25: 3389-3402.

Backhouse, D., and Willetts, H. J. 1987. Development and structure of infection cushions of Botrytis cinerea. Trans. Br. Mycol. Soc. 89:89-95.

Baudin, A., Ozier-Kalogeropoulos, O., Denouel, A., Lacroute, F., and Cullin, C. 1993. A simple and efficient method for direct gene deletion in Saccharomyces cerevisiae. Nucleic Acids Res. 21:3329-3330.

Buttner, P., Koch, F., Quidde, T., Risch, S., Blaich, R., Bruckner, B., and Tudzynski, P. 1994. Variation of ploidy levels within Botrytis cinerea isolates: Implication for genetic and molecular analyses. Curr. Genet. 25:445-450.

Carroll, A. N., Sweigard, J. A., and Valent, B. 1994. Improved vectors for selecting resistance to hygromycin. Fungal Genet. Newsl. 41:22.

Csank, C., Schroppel, K., Leberer, E., Harcus, D., Mohamedm, O., Meloche, S., Thomas, D. Y., and Whiteway, M. 1998. Roles of the Candida albicans mitogen-activated protein kinase homolog, Cek1, in hyphal development and systemic candidiasis. Infect. Immunol. 66: 2713-2721.

Cutler, H. G., Parker, S. R., Ross, S. A., Crumley, F. G., and Schreiner, P. R. 1996. Homobotcinolide: A biologically active natural homolog of Botcinolide from Botrytis cinerea. Biosci. Biotechnol. Biochem. 60: 656-658.

Dobinson, K. F., Harris, R. E., and Hamer, J. E. 1993. Grasshopper, a long terminal repeat (LTR) retroelement in the phytopathogenic fungus Magnaporthe grisea. Mol. Plant-Microbe Interact. 6:114-126.

Duran, P. R., Hernandes, G. R., Rebordinos, L. G., Cantoral, J. M., and Collado, J. 1999. Structure-activity relationships of new phytoxic metabolites with the botryane skeleton from Botrytis cinerea. Tetrahedron 55:2389-2400.

Elad, Y. 1997. Responses of plants to infection by Botrytis cinerea and novel means involved in reducing their susceptibility to infection. Biol. Rev. 72:381-422.

Guhad, F. A., Jensen, H. E., Aalbaek, B., Csank, C., Mohamed, O., Harcus, D., Thomas, D. Y., Whiteway, M., and Hau, J. 1998. Mitogenactivated protein kinase-defective Candida albicans is avirulent in a novel model of localized murine candidiasis. FEMS Microbiol. Lett. 166:135-139.

Gustin, M. C., Albertyn, J., Alexander, M., and Davenport, K. 1998. MAP kinase pathways in the yeast Saccharomyces cerevisiae. Microbiol. Mol. Biol. Rev. 62:1264-1300.

Hammer, P. E., and Evensen, K. B. 1994. Differences between rose cultivars in susceptibility to infection by Botrytis cinerea. Phytopathology $84: 1305-1312$.

Herskowitz, I. 1995. MAPK kinase pathways in yeast: For mating and more. Cell 80:187-197.

Irelan, J., Miao, V., and Selker, E. U. 1993. Small scale DNA preps for Neurospora crassa. Fungal Genet. Newsl. 40:24.

Jarvis, W. R. 1977. Botryotinia and Botrytis species: Taxonomy, physiology and pathogenicity. Canada Department of Agriculture, Ottawa, Ontario, Canada.

Kahmann, R., Basse, C., and Feldbrugge, M. 1999. Fungal-plant signal- ling in the Ustilago maydis-maize pathosystem. Curr. Opin. Microbiol. 2:647-650.

Krisak, L., Strich, R., Winters, R. S., Hall, J. P., Mallory, M. J., Krietzer, D., Tuan, R. S., and Winter, E. 1994. SMK1, a developmentally regulated MAP kinase, is required for spore wall assembly in Saccharomyces cerevisiae. Genes Dev. 8:2151-2161.

Lev, S., Sharon, A, Hadar, R., Ma, H., and Horwitz, B. A. 1999. A mitogen-activated protein kinase of the corn leaf pathogen Cochliobolus heterostrophus is involved in conidiation, appressorium formation, and pathogenicity: Diverse roles for mitogen-activated protein kinase homologs in foliar pathogens. Proc. Natl. Acad. Sci. USA 96:1354213547.

Levis, C., Fortini, D., and Brygoo, Y. 1997. Transformation of Botrytis cinerea with the nitrate reductase gene (niaD) shows a high frequency of homologous recombination. Curr. Genet. 32:157-162.

Li, D., Rogers, L., and Kolattukudy, P. E. 1997. Cloning and expression of cDNA encoding a mitogen-activated protein kinase from a phytopathogenic filamentous fungus. Gene 195:161-166.

Lurie, S., Fallik, E., Handros, A., and Shapira, R. 1997. The possible involvement of peroxidase in resistance to Botrytis cinerea in heat treated tomato fruit. Physiol. Mol. Plant Pathol. 50:141-149.

Madhani, H. D., Galitski, T., and Fink, G. R. 1999. Effectors of a developmental mitogen-activated protein kinase cascade revealed by expression signatures of signaling mutants. Proc. Natl. Acad. Sci. USA 96:12530-12535.

Mattern, I. E., Punt, P. J., and van dern Hondel, C. A. M. J. J. 1988. A vector of Aspergillus transformation conferring phleomycin resistance. Fungal Genet. Newsl. 35:25.

Mayorga, M. E., and Gold, S. E. 1999. A MAP kinase encoded by the $u b c 3$ gene of Ustilago maydis is required for filamentous growth and full virulence. Mol. Microbiol. 34:485-497.

Muller, P., Aichinger, C., Feldbrugge, M., and Kahmann, R. 1999. The MAP kinase Kpp2 regulates mating and pathogenic development in Ustilago maydis. Mol. Microbiol. 34:1007-1017.

Pelech, S. L. 1996. Signaling pathways: Kinase connections on the cellular intranet. Curr. Biol. 6:551-554.

Rebordinos, L., Cantoral, J. M., Prieto, M. V., Hanson, H. R., and Collado, I. G. 1996. The phytotoxic activity of some metabolites of Botrytis cinerea. Phytochemistry 42:383-387.

Rijkenberg, F. H. J., De Leeuw, G. T. N., and Verhoeff, K. 1980. Light and electron microscopy studies on the infection of tomato fruits by Botrytis cinerea. Can. J. Bot. 58:1394-1404.

Robinson, M. J., and Cobb, M. H. 1997. Mitogen-activated protein kinase pathways. Curr. Opin. Cell Biol. 9:180-186.

Staples, R. C., and Mayer, A. M. 1995. Putative virulence factors of Botrytis cinerea acting as a wound pathogen. FEMS Microbiol. Lett. 134:1-7.

Takano, Y., Kikuchi, T., Kubo, Y., Hamer, J. E., Mise, K., and Furusawa I. 1999. The MAP kinase gene CMK1 of Colletotrichum lagenarium regulates germination, appressorium formation, and invasive growth. (Abstr.) IS-MPMI Int. Congr., 9th.

ten Have, A., Mulder, W., Visser, J., and van Kan, J. A. L. 1998. The endopolygalacturonase gene Bcpgl is required for full virulence of Botrytis cinerea. Mol. Plant-Microbe Interact. 11:1009-1016.

Tiedemann, A. V. 1997. Evidence for a primary role of active oxygen species in induction of host cell death during infection of bean leaves with Botrytis cinerea. Physiol. Mol. Plant Pathol. 50:151-166.

van Kan, J. A. L., van't Klooster, J. W., Wagemakers, C. A. M., Dees, D. C. T., and van der Vlugt-Bergmans, C. J. B. 1997. Cutinase A of Botrytis cinerea is expressed, but not essential, during penetration of gerbera and tomato. Mol. Plant-Microbe Interact. 10:30-38.

Verhoeff, K. 1980. The infection process and host-pathogen interactions. Pages 153-180 in: Biology of Botrytis. J. R. Coley-Smith, K. Verhoeff, and W. R. Jarvis, eds. Academic Press, New York.

Wubben, J. P., Mulder, W., ten Have, A., van Kan, J. A. L., and Visser, J. 1999. Cloning and partial characterization of endopolygalacturonase genes from Botrytis cinerea. Appl. Environ. Microbiol. 65:1596-1602.

Xu, J.-R., and Hamer, J. E. 1996. MAP kinase and cAMP signaling regulate infection structure formation and pathogenic growth in the rice blast fungus Magnaporthe grisea. Genes Dev. 10:2696-2706.

Xu, J.-R., Staiger, C. J., and Hamer J. E. 1998. Inactivation of the mitogen-activated protein kinase MPS1 in the rice blast fungus prevents penetration of host cells but allows activation of plant defense responses. Proc. Natl. Acad. Sci. USA 95:12713-12718. 